\title{
Effects of temperature on the composition and diversity of bacterial communities in bamboo soils at different elevations
}

\author{
Yu-Te Lin ${ }^{1}$, Zhongjun Jia ${ }^{2}$, Dongmei Wang ${ }^{2}$, and Chih-Yu Chiu ${ }^{1}$ \\ ${ }^{1}$ Biodiversity Research Center, Academia Sinica, Taipei 11529, Taiwan \\ ${ }^{2}$ State Key Laboratory of Soil and Sustainable Agriculture, Institute of Soil Science, Chinese Academy of Sciences, \\ Nanjing 210008, People's Republic of China \\ Correspondence to: Zhongjun Jia (jia@issas.ac.cn) and Chih-Yu Chiu (bochiu@ sinica.edu.tw)
}

Received: 30 March 2017 - Discussion started: 18 April 2017

Revised: 11 September 2017 - Accepted: 21 September 2017 - Published: 6 November 2017

\begin{abstract}
Bamboo is an important resource distributed in mountain areas in Asia. Little is known about the impact of temperature changes on bamboo soil bacterial communities. In this study, responses of bacterial communities collected at 600,1200 , and $1800 \mathrm{~m}$ to different incubation temperatures $\left(15,20\right.$, and $\left.35^{\circ} \mathrm{C}\right)$ were examined using barcoded pyrosequencing and soil analyses. Soil respiration was greater at higher elevation and incubation temperature. The bacterial diversity decreased after 112 days of incubation at $35^{\circ} \mathrm{C}$. Before incubation, Acidobacteria and Proteobacteria were the most abundant phyla in all communities. The relative abundance of Acidobacteria generally decreased after 112 days of incubation at the three temperatures. $\alpha$-Proteobacteria showed a similar trend, while $\gamma$-Proteobacteria increased after incubation, except in samples from $1800 \mathrm{~m}$ incubated at $35^{\circ} \mathrm{C}$. Non-metric multi-dimensional scaling analysis revealed structural variability under different incubation times and temperatures. Principal component analysis indicated that the bacterial structure in samples incubated at $35^{\circ} \mathrm{C}$ correlated with temperature and soil respiration, while structures in samples incubated at 15 and $20^{\circ} \mathrm{C}$ correlated with time. These results suggest that a temperature rise could result in increasing soil respiration and soluble carbon and nitrogen consumption as well as differentially influence bacterial diversity and structure at different elevations.
\end{abstract}

\section{Introduction}

Temperature is one of the most important factors influencing soil organic matter decomposition and microbial communities. For example, temperature significantly affects the soil microbial phospholipid fatty acid composition associated with straw decomposition at the early stage (Zhou et al., 2016). Bacterial abundance increases in conditions of elevated temperature and $\mathrm{CO}_{2}$ concentration (Castro et al., 2010). The complex responses of bacterial composition and diversity of bamboo soils across altitudinal gradients have been suggested to result from interactions with multiple factors, including temperature (Lin et al., 2015).

In Taiwan, moso bamboo (Phyllostachys pubescens) is an important versatile forest resource that is widely used for food, construction, and as a furniture material. It is distributed from low- to high-mountain regions at approximately $1800 \mathrm{~m}$ above sea level (a.s.1.). Management practices for increasing bamboo production, including regular removal of understory vegetation, tillage, and fertilizer application, can increase the soil $\mathrm{CO}_{2}$ efflux (Liu et al., 2011) and watersoluble organic $\mathrm{N}$ concentration (Wu et al., 2010). However, these management practices can lower the microbial functional diversity ( $\mathrm{Xu}$ et al., 2008). Considering the effects of bamboo plantations on soil properties and microbial communities, it is worth elucidating the changes in bamboo soil bacterial communities under environmental changes.

Our previous study revealed that bamboo invasion could increase bacterial diversity and alter the bacterial structure of adjacent cedar forest soils (Lin et al., 2014). Soil bacterial diversity in bamboo plantations showed a hump-backed trend, with less diversity at low and high elevations, and max- 
imum diversity at middle elevations, and community structure formed different clusters at different elevations (Lin et al., 2015). Our parallel study showed that invasion of bamboo into adjacent forest soils increased humification of soil organic matter (SOM) (Wang et al., 2016b). In addition, changes in the SOM pool and the rate of humification with elevation were primarily affected by changes in climatic conditions along the elevation gradient in the bamboo plantations (Wang et al., 2016a). However, it is not known whether bamboo soil bacterial groups respond to temperature changes.

Soil bacterial communities include different phylotypes that likely represent different functional groups, and their relative abundances are affected by carbon (C) availability. For example, some members of Proteobacteria are considered copiotrophs, and their relative abundances appear to be higher in C-rich environments. In contrast, oligotrophs (e.g., Acidobacteria) can live in stressful environmental conditions (Fierer et al., 2007). However, little is known about how these two groups respond to the environmental temperature changes. Here, we hypothesized that the temperature changes would alter the structure and diversity of soil bacterial communities at different elevations, and that bacterial taxa, including copiotrophic and oligotrophic groups, would have distinct responses to altered nutrient availability caused by temperature changes. To test these hypotheses, soil communities sampled at bamboo plantations at three elevations were incubated at different temperatures and investigated by using the barcoded pyrosequencing technique. The objectives of this study were to elucidate (1) changes in soil organic carbon, nitrogen, and respiration at elevation gradients and at different incubation temperatures, (2) differences in bacterial structure and diversity under different incubation temperatures and periods, and (3) changes in the abundances of different phylogenetic groups at different incubation temperatures.

\section{Methods}

\subsection{Site description and soil sampling}

This study was conducted in Mt. Da'an, a subtropical mountain area in Nantou County, central Taiwan $\left(23^{\circ} 42^{\prime} \mathrm{N}\right.$, $120^{\circ} 41^{\prime} \mathrm{E}$ ). The soil samples were collected from moso bamboo plantations at 600,1200 , and 1800 ma.s.l. along a county road. The three sampling sites were all dominated by moso bamboo with few understory plants. Based on weather station records and the temperature-elevation correlation, the annual mean air temperature was estimated as $20.3^{\circ} \mathrm{C}$ at $600 \mathrm{~m}, 17.2^{\circ} \mathrm{C}$ at $1200 \mathrm{~m}$, and $14.1^{\circ} \mathrm{C}$ at $1800 \mathrm{~m}$ with a decrease of $0.52{ }^{\circ} \mathrm{C}$ per $100 \mathrm{~m}$ elevation gain (Wang et al., 2016a). At each elevation, three $25 \mathrm{~m} \times 25 \mathrm{~m}$ plots were established along transect lines in March 2015. Within each plot, three subsamples were collected with a soil auger $8 \mathrm{~cm}$ in diameter and $10 \mathrm{~cm}$ deep and pooled. Visible detritus, such as roots and litter, was manually removed prior to passing the soil through a $2 \mathrm{~mm}$ sieve. Soil samples collected at each elevation were combined and homogenized for further incubation and analysis. The sieved soils were stored at $4{ }^{\circ} \mathrm{C}$ before incubation experiments.

\subsection{Incubation experiment and soil analysis}

Three replicates $(25 \mathrm{~g}$ each) from each elevation were incubated at 15,20 , or $35^{\circ} \mathrm{C}$ for 112 days. The temperatures of 15 and $20^{\circ} \mathrm{C}$ were selected based on the mean annual temperature, while $35^{\circ} \mathrm{C}$ was selected to simulate the summer condition. During the entire incubation period, the soil moisture was maintained at $60 \%$ of the water-holding capacity. At various incubation times, soil samples were taken from the same container. Soil respiration $\left(\mathrm{CO}_{2}-\mathrm{C}\right)$ was measured as described (Huang et al., 2014). Soluble organic carbon (SOC) and nitrogen (SON) were extracted from the soil samples after different incubation periods with $2 \mathrm{M} \mathrm{KCl}$ and measured with the Fisons NA1500 elemental analyzer (ThermoQuest Italia, Milan, Italy) as described (Huang et al., 2014).

\subsection{Barcoded pyrosequencing of the $16 \mathrm{~S}$ rRNA genes}

Soil community DNA was extracted using the PowerSoil ${ }^{\circledR}$ soil DNA isolation kit (MoBio Industries, Carlsbad, CA, USA) in accordance with the manufacturer's instructions. The V1 to V2 regions of the bacterial 16S rRNA gene were amplified using 27F and 338R primers (Lane, 1991). Polymerase chain reactions (PCR) were performed as described previously (Lin et al., 2015). Secondary PCR (using 3 cycles instead of 20) was carried out to barcode the DNA in each sample. The unique and error-correcting barcodes facilitated sorting of sequences from a single pyrosequencing run (Hamady et al., 2008). The barcoded PCR products were purified on a column filter using a PCR clean-up system (Viogene Biotek Corp., New Taipei City, Taiwan). The qualities and concentrations of the purified barcoded PCR products were determined using a NanoDrop spectrophotometer (Thermo Fisher Scientific, Waltham, MA, USA). Amplicon pyrosequencing was performed by Mission Biotech (Taipei, Taiwan) using the 454/Roche GS-FLX Titanium instrument (Roche, Branchburg, NJ, USA). All sequences have been submitted to the Short Read Archives under accession number SRS1923345.

\subsection{Sequence analyses}

The pyrosequences were processed through the RDP pyrosequencing pipeline (http://pyro.cme.msu.edu; RDP Release 11.5; release date: 30 September 2016). The sequences were assigned to the samples by recognition of the barcode from a tag file, followed by trimming of barcodes, primers, and linkers. The pyrosequences were filtered, and sequences that did not contain Ns, were more than 200 bp in length, and possessed quality scores $>25$ were selected for further 
analyses. Taxonomic information was analyzed using the naïve Bayesian rRNA classifier in RDP (Wang et al., 2007). The Shannon diversity index was calculated based on complete linkage clustering data for operational taxonomic units (OTUs), with an evolutionary distance of 0.03 . The distribution of shared OTUs among the communities was obtained using the Mothur program (Schloss et al., 2009). Nonmetric multi-dimensional scaling (NMDS) based on the distribution of shared OTUs was plotted by using the PRIMER V6 software (Clarke and Gorley, 2006). The Mantel tests as implemented in PRIMER V6 software was used to analyze the relationships between bacterial communities, phylogenetic groups and soil properties. Principal component analysis (PCA) to determine the relationship between bacterial community and soil properties was carried out using R v.3.2.1.

\section{Results}

\subsection{Soil respiration, SOC, and SON}

Data on soil respiration $\mathrm{CO}_{2}-\mathrm{C}$ in samples taken from three elevations and incubated at different temperatures are shown in Fig. 1. Under the same temperature, the soil samples collected at higher elevation, especially those from $1800 \mathrm{~m}$, had a significantly higher soil respiration rate than those obtained at lower elevation. The soil respiration rate increased with temperature within each elevation. At $35^{\circ} \mathrm{C}$, the soil respiration rate decreased significantly with incubation time. At 15 and $20^{\circ} \mathrm{C}$, the respiration rates of some soil samples slightly increased in the early incubation period (until day 28, d28) (Fig. 1). Because the respiration rate was stabilized after $\mathrm{d} 72$, respiration rate analyses were conducted only up to this time point.

At d0, the SOC and SON contents of the soils increased significantly with elevation (Fig. 2). Compared to d0, the concentration of SOC in the high-elevation soils $(1800 \mathrm{~m})$ decreased, while those at 600 and $1200 \mathrm{~m}$ increased after 112 days (d112) of incubation at three temperatures. Incubation at higher temperature $\left(35^{\circ} \mathrm{C}\right)$ resulted in higher SOC content than that at lower temperatures $\left(15\right.$ and $\left.20^{\circ} \mathrm{C}\right)$. In most samples, SON content increased until d28 of incubation, but was decreased at $\mathrm{d} 112$.

\subsection{Community diversity at different temperatures}

The soil bacterial diversity at three elevations at different incubation temperatures was determined based on an OTU cutoff of $\leq 0.03$. Based on the Shannon diversity index, the bacterial diversity of soils incubated at $35^{\circ} \mathrm{C}$ decreased after long incubation (d112). Under incubation at 15 or $20^{\circ} \mathrm{C}$, the bacterial diversity slightly increased at $\mathrm{d} 7$ and $\mathrm{d} 28$, and decreased at d112 (Fig. 3). Analysis of the $\beta$-diversity revealed that though incubated with different temperature, the
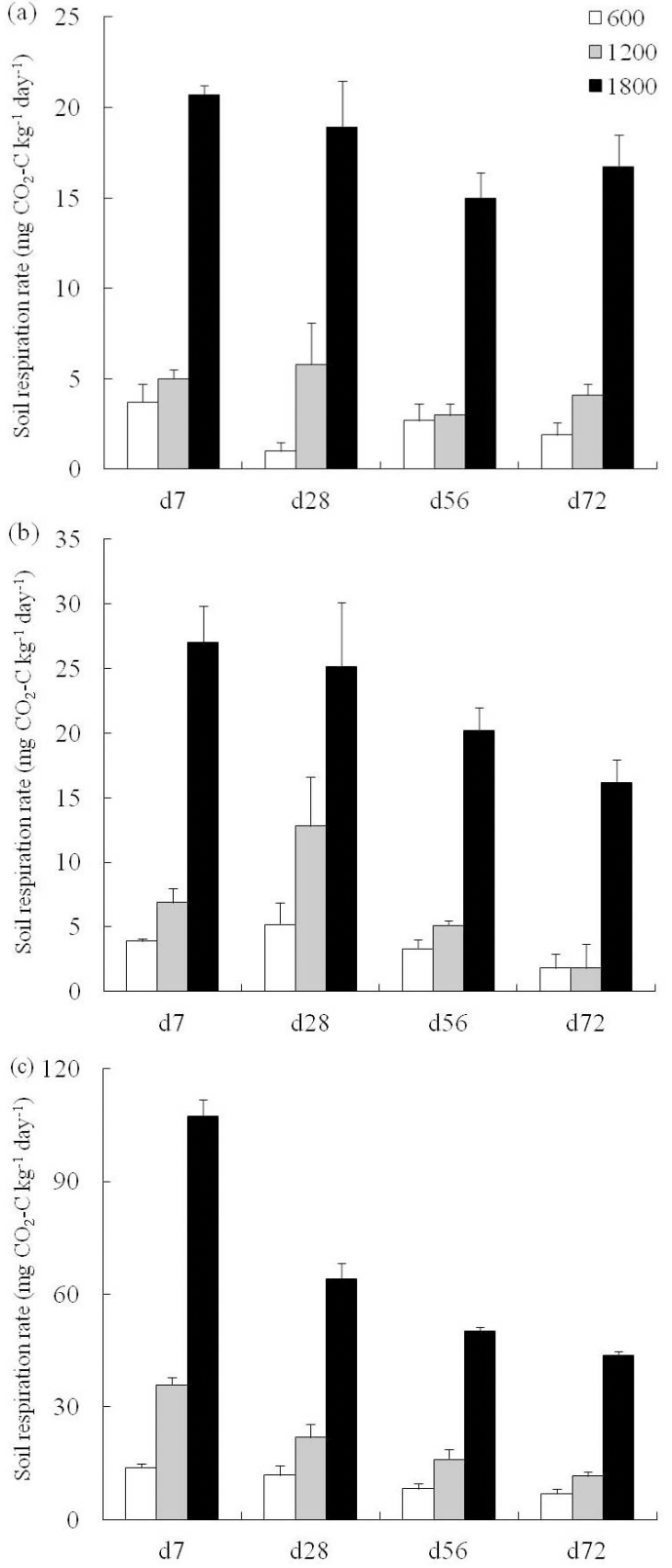

Figure 1. Respiration $\mathrm{CO}_{2}-\mathrm{C}$ rate in soils sampled at three elevations under incubation at (a) $15^{\circ} \mathrm{C}$, (b) $20^{\circ} \mathrm{C}$, and (c) $35^{\circ} \mathrm{C}$. Error bars represent SD.

communities at the same elevation formed a cluster different from those at other elevations (Supplement Fig. S1).

\subsection{Community composition at different incubation temperatures}

Before incubation, Acidobacteria and Proteobacteria were the two most abundant phyla in soils from all three eleva- 

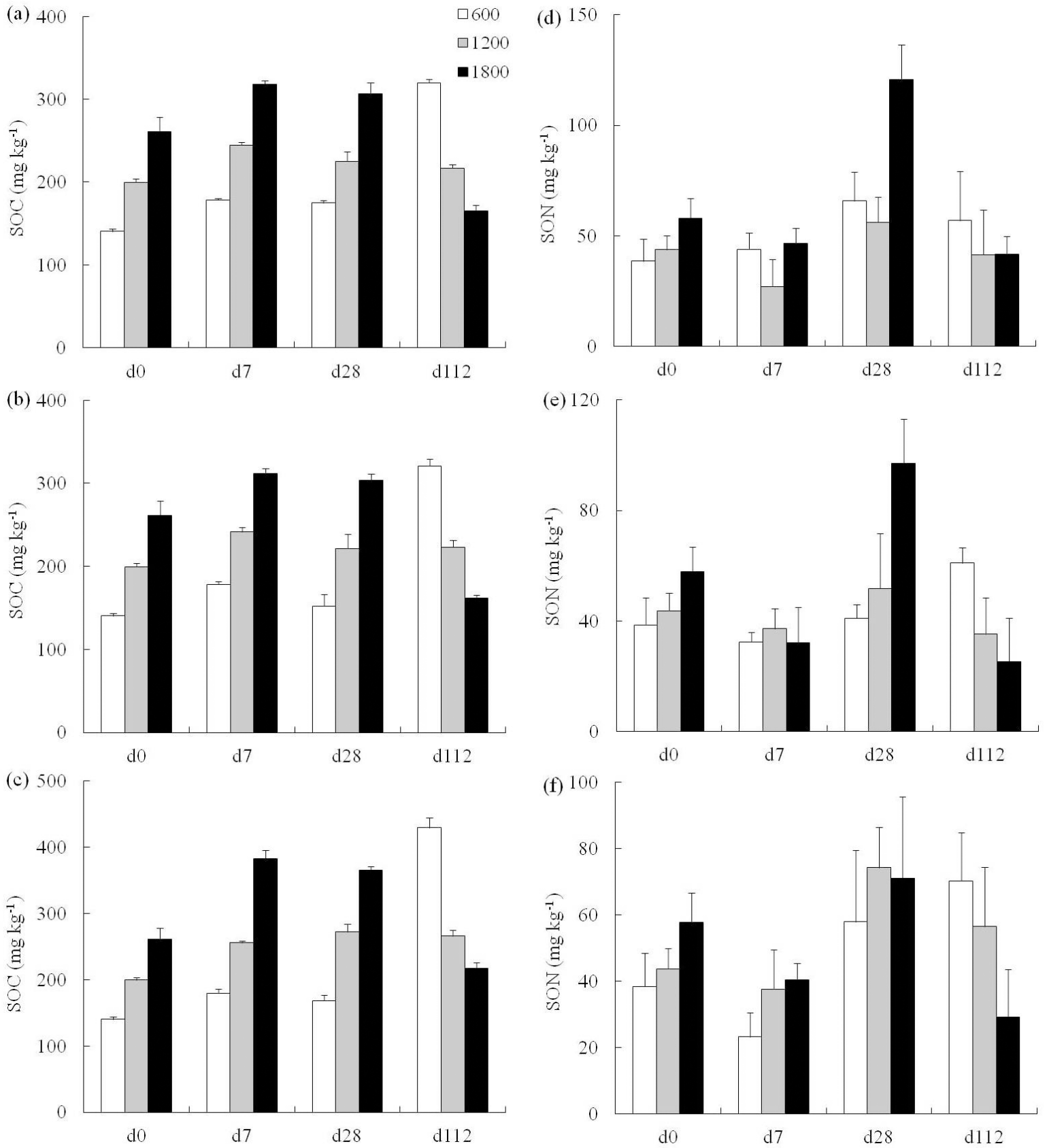

Figure 2. Concentration of (a-c) soluble organic carbon (SOC) and (d-f) nitrogen (SON) in bamboo soils sampled at three elevations and incubated at $(\mathbf{a}, \mathbf{d}) 15^{\circ} \mathrm{C},(\mathbf{b}, \mathbf{e}) 20^{\circ} \mathrm{C}$, and $(\mathbf{c}, \mathbf{f}) 35^{\circ} \mathrm{C}$. Error bars represent standard deviation.

tions, together representing more than $60 \%$ of the soil bacterial communities (Table 1). Within the Proteobacteria, $\alpha$ Proteobacteria were predominant (Table 1). At $1800 \mathrm{~m}$, Bacteroidetes accounted for $8 \%$ of the community, while they comprised only $2-4 \%$ of the communities at the two other elevations. The relative abundance of Actinobacteria was 4$6 \%$, and the other phylogenetic groups represented less than $3 \%$ of the communities.
Bacterial groups of the soil communities showed different responses to the incubation temperature. The relative abundance of Acidobacteria at 600 and $1200 \mathrm{~m}$ gradually decreased over the entire incubation period at all temperatures (Fig. 4a-f). At $1800 \mathrm{~m}$, it increased during the first 7 days of incubation at $35^{\circ} \mathrm{C}$, and decreased thereafter at all temperatures (Fig. 4i). The relative abundance of $\alpha$-Proteobacteria showed similar trends; it gradually decreased at 600 and $1200 \mathrm{~m}$ over the entire incubation period at different tempera- 

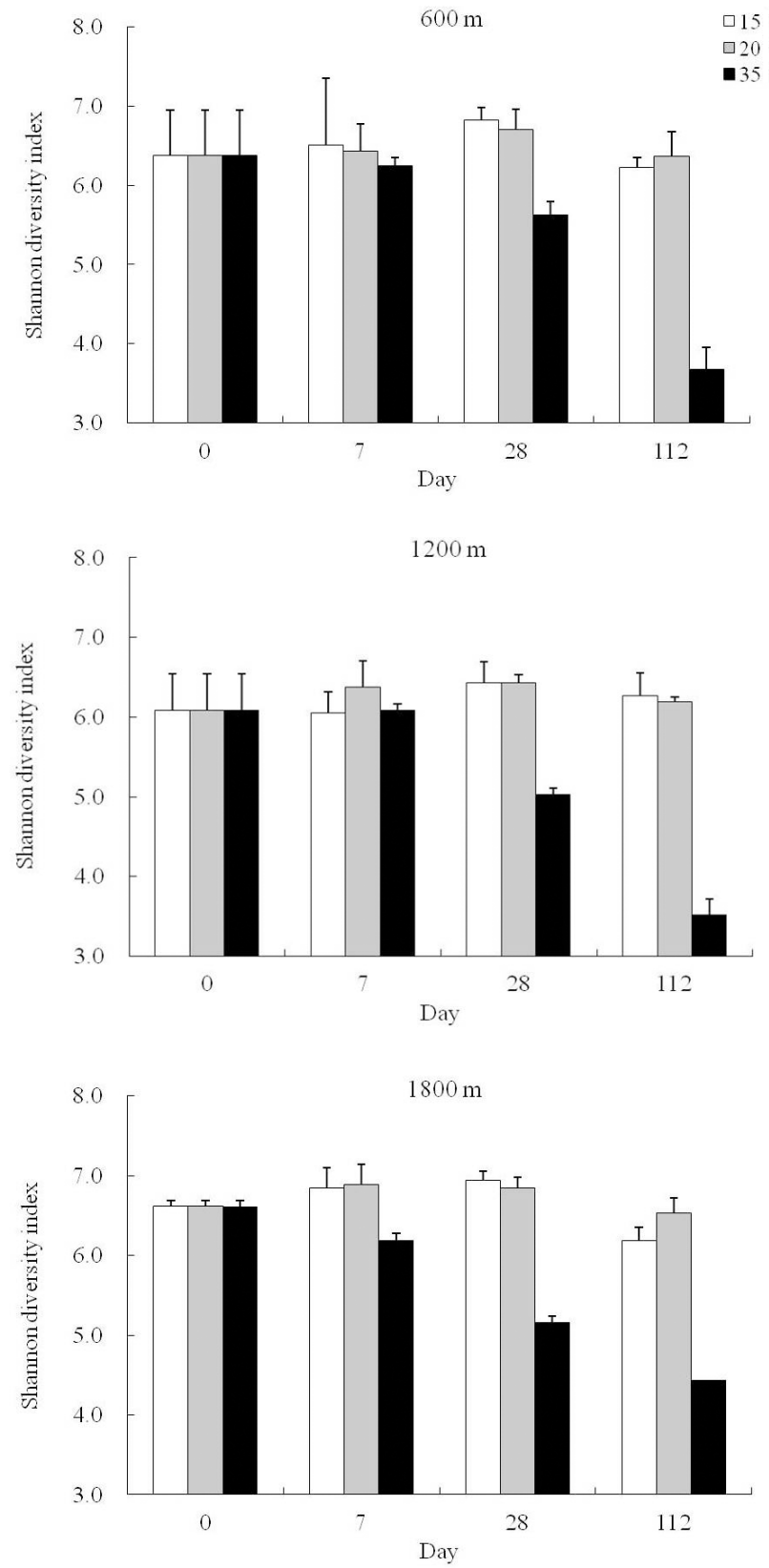

Figure 3. Changes in bacterial diversity of soil community at 600 , 1200 , and $1800 \mathrm{~m}$ incubated at different temperatures.

tures, except at $\mathrm{d} 7$ at $600 \mathrm{~m}, 20^{\circ} \mathrm{C}$, and at $\mathrm{d} 7$ at $1200 \mathrm{~m}, 35^{\circ} \mathrm{C}$ (Fig. 4a-f). At $1800 \mathrm{~m}$, the changes in abundance were different. $\alpha$-Proteobacteria were elevated at $\mathrm{d} 7$ and $\mathrm{d} 112$, but were lower at $\mathrm{d} 28$ of incubation at 15 and $20^{\circ} \mathrm{C}$. Their abundance decreased over time under incubation at $35^{\circ} \mathrm{C}$ (Fig. $4 \mathrm{~g}-\mathrm{i}$ ). With regard to $\gamma$-Proteobacteria, their relative abundance mostly increased over incubation, except in soils sampled at $1800 \mathrm{~m}$ under incubation at $35^{\circ} \mathrm{C}$, in which it was increased at $\mathrm{d} 7$ but decreased at $\mathrm{d} 28$ and $\mathrm{d} 112$ (Fig. 4i). The relative abundance of Chloroflexi also increased over incubation, ex-

Table 1. Relative abundances (\%) of different phylogenetic groups in the bamboo soil bacterial communities at different elevations.

\begin{tabular}{lrrr}
\hline Phylogenetic groups & $600 \mathrm{~m}$ & $1200 \mathrm{~m}$ & $1800 \mathrm{~m}$ \\
\hline Acidobacteria & 46.9 & 43.6 & 39.8 \\
Actinobacteria & 5.5 & 6.9 & 4.3 \\
Bacteroidetes & 4.3 & 2.0 & 8.1 \\
Chloroflexi & 3.3 & 3.4 & 1.7 \\
Firmicutes & 1.1 & 0.6 & 0.7 \\
Gemmatimonadetes & 0.8 & 1.2 & 1.8 \\
Nitrospirae & 1.2 & 0.6 & 0.5 \\
Alphaproteobacteria & 11.4 & 13.0 & 15.3 \\
Betaproteobacteria & 3.2 & 1.4 & 4.4 \\
Gammaproteobacteria & 3.1 & 1.9 & 2.2 \\
Deltaproteobacteria & 1.4 & 0.9 & 1.3 \\
Proteobacteria, others & 6.2 & 6.3 & 7.1 \\
Others & 11.6 & 18.2 & 12.8 \\
\hline
\end{tabular}

cept in samples taken at $600 \mathrm{~m}$, incubated at $15^{\circ} \mathrm{C}$, on d112. Some other phyla demonstrated inconsistent changes under increased temperature. The abundances of Actinobacteria at 1200 and $1800 \mathrm{~m}$ increased at higher temperature (Fig. 4di), while it decreased in samples taken at $600 \mathrm{~m}$ (Fig. $4 \mathrm{a}-\mathrm{c}$ ). Likewise, Bacteroidetes showed inconsistent changes after different incubation times and temperatures (Fig. $4 \mathrm{a}-\mathrm{i}$ ).

The changes in relative abundance of some abundant genera are shown in Fig. 5. The relative abundance of acidobacterial-GP1 generally decreased over the entire incubation period at all temperatures, except at $35^{\circ} \mathrm{C}$ (Fig. 5i). The $\alpha$-proteobacterial Bradyrhizobium showed similar trends, while its relative abundance at $1800 \mathrm{~m}$ increased at all three incubation temperatures (Fig. 5gi). Within $\beta$-Proteobacteria, the relative abundance of Burkholderia at $1200 \mathrm{~m}$ decreased over incubation, except in samples incubated at $15^{\circ} \mathrm{C}$ in the first 7 days (Fig. 5d). With regard to $\gamma$-Proteobacteria, Dyella in samples from $1200 \mathrm{~m}$ decreased under all three incubation temperatures (Fig. 5d-f), and its abundance increased mostly in communities at $600 \mathrm{~m}$ and $1800 \mathrm{~m}$ (Fig. 5a-c and g-i). The relative abundance of Mucilaginibacter of Bacteroidetes at $1800 \mathrm{~m}$ increased greatly in samples incubated at $35^{\circ} \mathrm{C}$ on $\mathrm{d} 28$ and d112 (Fig. 5i)

NMDS analysis based on the distribution of shared OTUs also revealed the variability in bacterial structure under different incubation times and temperatures (Fig. 6). The bacterial community at $1800 \mathrm{~m}$ formed a different cluster from those at 600 and $1200 \mathrm{~m}$. Incubation at higher temperature $\left(35^{\circ} \mathrm{C}\right)$ led to a bacterial structure different from those at 15 and $20^{\circ} \mathrm{C}$. Incubation time also changed the bacterial structure. The bacterial structure under long incubation (at d112) was different from those at $\mathrm{d} 7$ and $\mathrm{d} 28$.

PCA revealed the correlation between bacterial structure and environmental factors. When incubated at $35^{\circ} \mathrm{C}$, bacterial structure correlated with temperature and soil respiration 

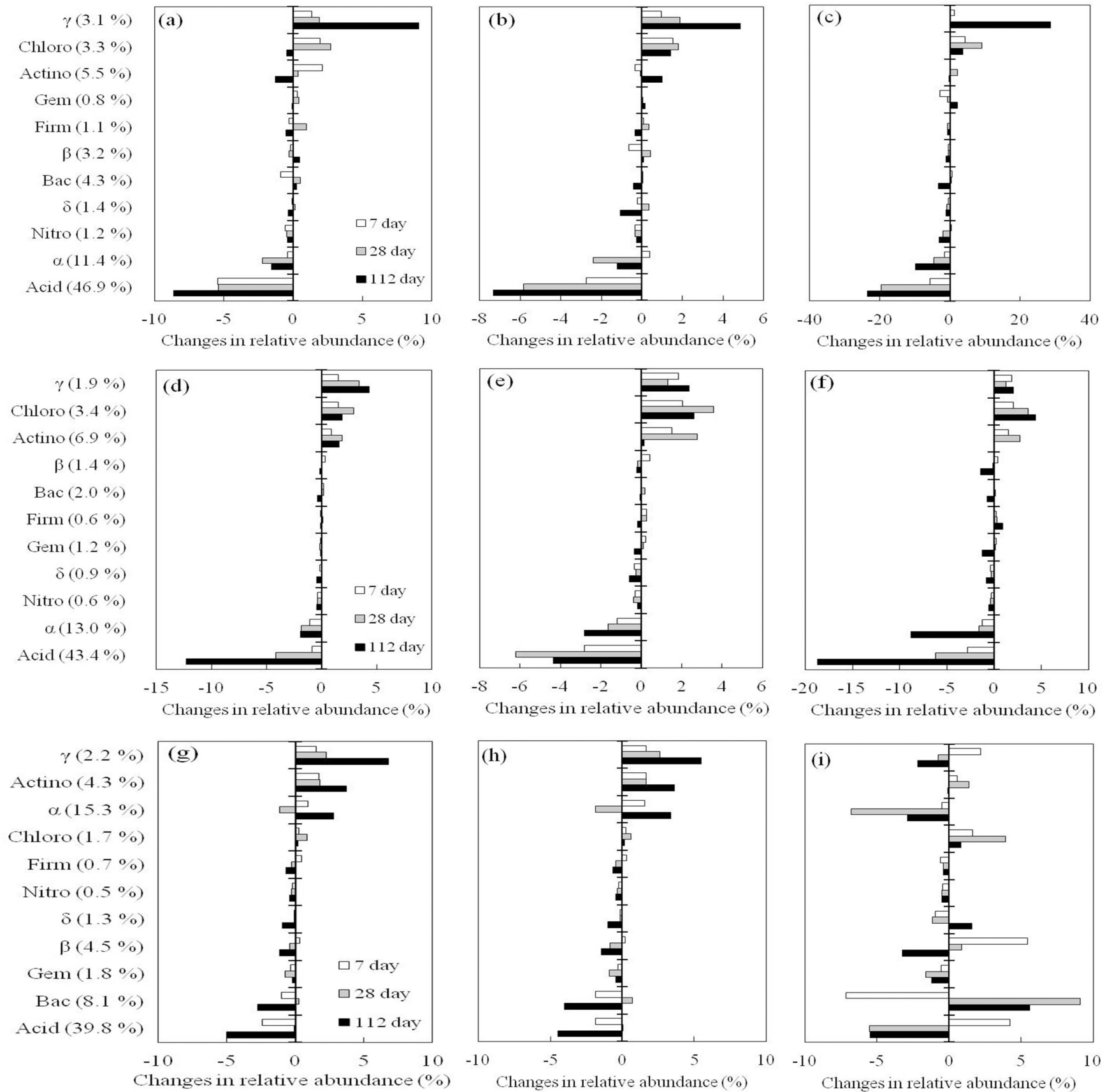

Figure 4. Changes in relative abundance of phylogenetic groups of bamboo soil bacterial communities at (a) $600 \mathrm{~m}, 15^{\circ} \mathrm{C}$; (b) $600 \mathrm{~m}, 20^{\circ} \mathrm{C}$; (c) $600 \mathrm{~m}, 35^{\circ} \mathrm{C}$; (d) $1200 \mathrm{~m}, 15^{\circ} \mathrm{C}$; (e) $1200 \mathrm{~m}, 20^{\circ} \mathrm{C}$; (f) $1200 \mathrm{~m} ; 35^{\circ} \mathrm{C}$, (g) $1800 \mathrm{~m}, 15^{\circ} \mathrm{C}$; (h) $1800 \mathrm{~m}, 20^{\circ} \mathrm{C}$; and (i) $1800 \mathrm{~m}, 35^{\circ} \mathrm{C}$. Abbreviation: Acid: Acidobacteria; Actino: Actinobacteria; Bac: Bacteroidetes; Chloro: Chloroflexi; Firm: Firmicutes; Gem: Gemmatimonadetes; Nitro: Nitrospirae; $\alpha, \beta, \gamma, \delta: \alpha-, \beta-, \gamma$-, and $\delta$-Proteobacteria.

$\mathrm{CO}_{2}-\mathrm{C}$, while at 15 and $20^{\circ} \mathrm{C}$, bacterial structure correlated with incubation time (Fig. 7).

\section{Discussion}

The present study revealed that the SOC content was higher at high incubation temperature and decreased with increasing elevation after long incubation. The soil respiration $\mathrm{CO}_{2}-$ $\mathrm{C}$ rate was greater at higher elevation. Similarly, a previous study in tundra soils using different incubation temperatures 

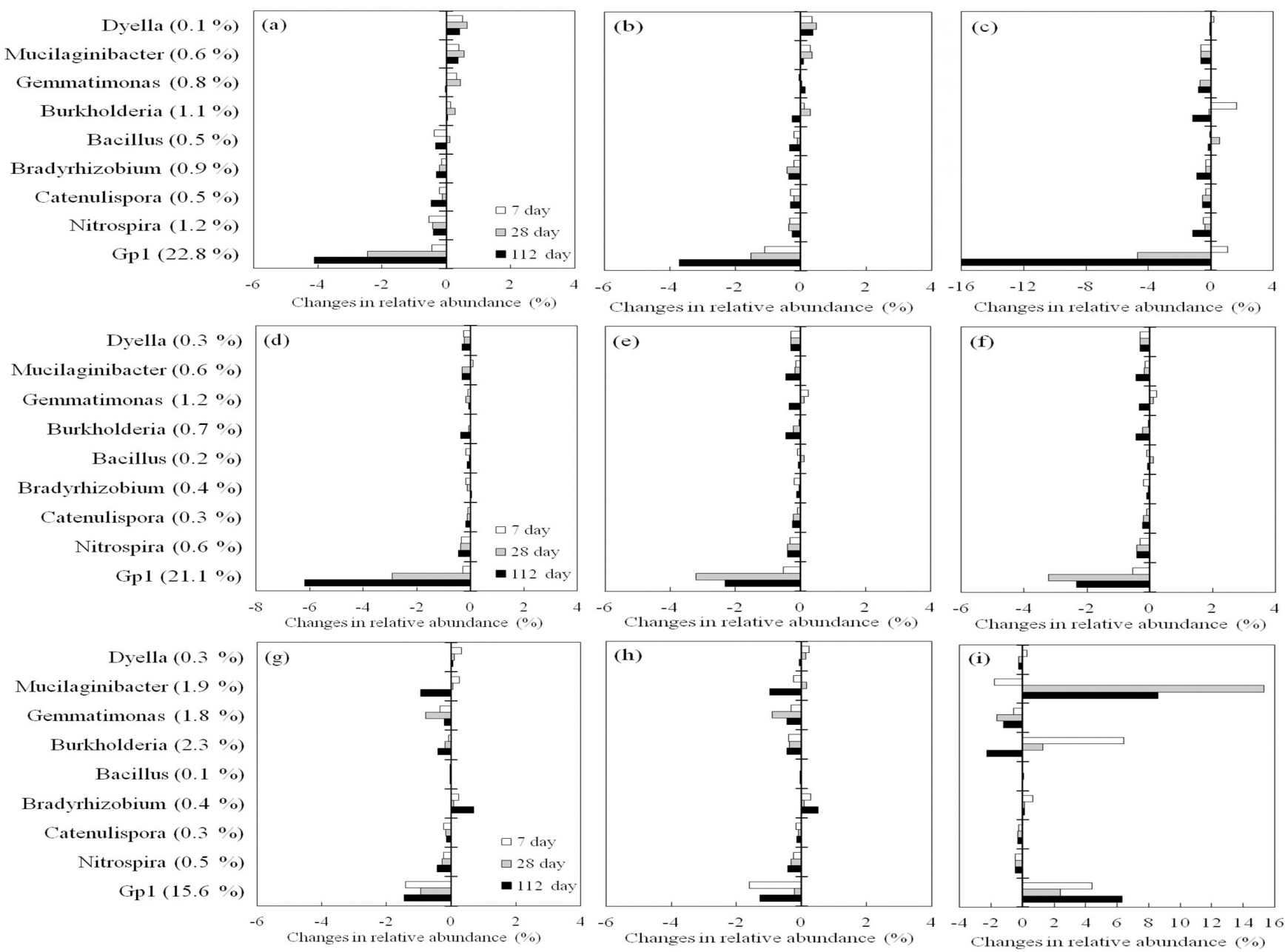

Figure 5. Changes in relative abundance of abundant genera of bamboo soil bacterial communities at (a) $600 \mathrm{~m}, 15^{\circ} \mathrm{C} ;(\mathbf{b}) 600 \mathrm{~m}, 20^{\circ} \mathrm{C}$; (c) $600 \mathrm{~m}, 35^{\circ} \mathrm{C}$; (d) $1200 \mathrm{~m}, 15^{\circ} \mathrm{C}$; (e) $1200 \mathrm{~m}, 20^{\circ} \mathrm{C}$; (f) $1200 \mathrm{~m}, 35^{\circ} \mathrm{C}$; (g) $1800 \mathrm{~m}, 15^{\circ} \mathrm{C}$; (h) $1800 \mathrm{~m}, 20^{\circ} \mathrm{C}$; and (i) $1800 \mathrm{~m}, 35^{\circ} \mathrm{C}$.

reported higher respiration rate at high temperatures (Stark et al., 2015). Incubation at increasing temperatures enhanced the soil microbial activity and led to an increase in soil respiration in forest mesocosms (Lin et al., 2001). In our study, the respiration rate decreased after long incubation. This could be due to the exhaustion of labile compounds after microbial decomposition (Zhou et al., 2016). The decrease in bacterial diversity at high elevation and high incubation temperature, calculated from abundance data of the phylogenetic groups, could also be the result of nutrient exhaustion after long incubation. In addition, the correlation between soil respiration and bacterial structure in the soil samples under incubation at $35^{\circ} \mathrm{C}$ suggests the adaption and high activity of bacterial communities at higher temperature.

In d0 samples, which represent the original composition of the bamboo soils, the bacterial diversity was higher in the $1800 \mathrm{~m}$ soils, followed by the 600 and $1200 \mathrm{~m}$ soils. Communities with higher diversity are reportedly more resistant to environmental changes (Loreau and de Mazancourt, 2013).
In a study by Ren et al. (2015) in rice paddies, the diverse soil communities were more resistant to elevated $\mathrm{CO}_{2}$ and temperature than the less diverse foliar bacterial communities. The increasing concentration of recalcitrant $\mathrm{C}$ with increasing elevation (Wang et al., 2016a) could be helpful in providing more carbon resources to the community at high elevation. Together, these findings indicate that bamboo soil bacterial communities with higher diversity could be more capable of maintaining soil community and function when exposed to climatic changes and subjected to management at high elevation (1800 m).

The bacterial community structure varied over different incubation periods and temperatures. Based on the abundance data of phylogenetic groups, the communities at the three elevations formed different clusters as compared to the results of our previous study (Lin et al., 2015). The different soil bacterial structures at different elevations can be explained by differences in soil management. The effects of management practices on soil microbial community can persist over 


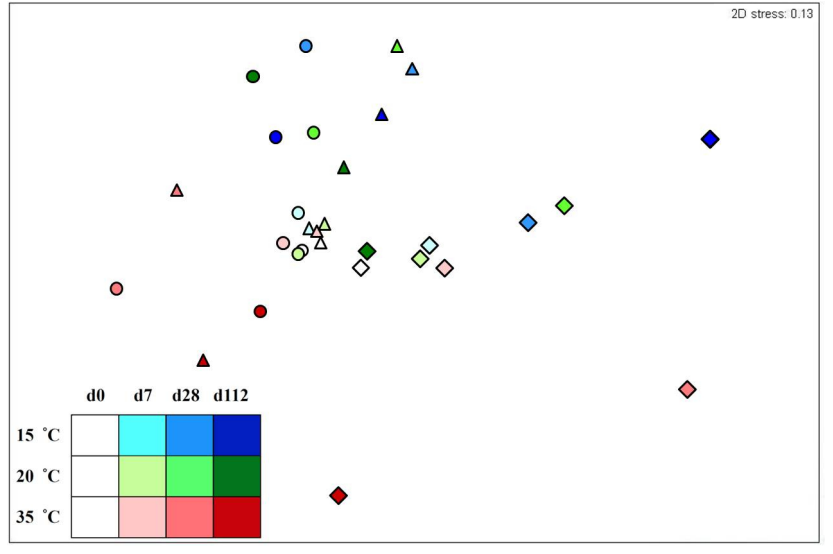

Figure 6. NMDS analysis of bamboo soil bacterial communities sampled at three elevations and incubated at different temperatures. Circles, triangles, and diamonds represent communities at 600,1200 , and $1800 \mathrm{~m}$ elevation, respectively. The analysis was based on the distribution of OTUs formed at an evolutionary distance of 0.03 .

time (Keiser et al., 2011). Recently, bamboo shoot harvest and timber production has moved from about 600 to $1200 \mathrm{~m}$ in the study area. Soils at different elevation have distinct soil SOC and SON contents, which could result in different forces to alter bacterial communities. Incubation temperature also had an effect on community structure. Warming in the experimental field in a previous study in the Arctic environment caused a significant increase in the abundance of fungi and bacteria (Yergeau et al., 2012). The quantity of SOC and $\mathrm{CO}_{2}$ flux has been shown to increase under warming conditions (Zhang et al., 2005; Zhou et al., 2011). Increasing temperature increased relative bacterial growth in arable soils from southern Sweden (Bárcenas-Moreno et al., 2009) and, particularly, the abundance of genes involved in labile carbon degradation in a tall-grass prairie ecosystem in central Oklahoma, USA (Zhou et al., 2011), and led to C loss. In the present study, the shifts in bacterial communities at three elevations could reflect differences in nutrient availability, including SOC and SON, and bacterial activity under different incubation temperatures and at distinct time points during incubation.

Bacterial community structure under incubation at $35^{\circ} \mathrm{C}$ was affected by temperature, while under incubation at 15 and $20^{\circ} \mathrm{C}$ it correlated with incubation time (Fig. 7). Warming has been shown to change the bacterial structure of alpine meadow soils (Xiong et al., 2014) and to cause thermaladaption functional shift of microbial communities (Rousk et al., 2012). Recent studies have observed changes in temperature sensitivity of microbial communities along incubation time. Shifts in microbial communities in response to warming occur after a few years (Yergeau et al., 2012) or even only a few months (Xiong et al., 2014). However, some studies revealed no significant community changes over time

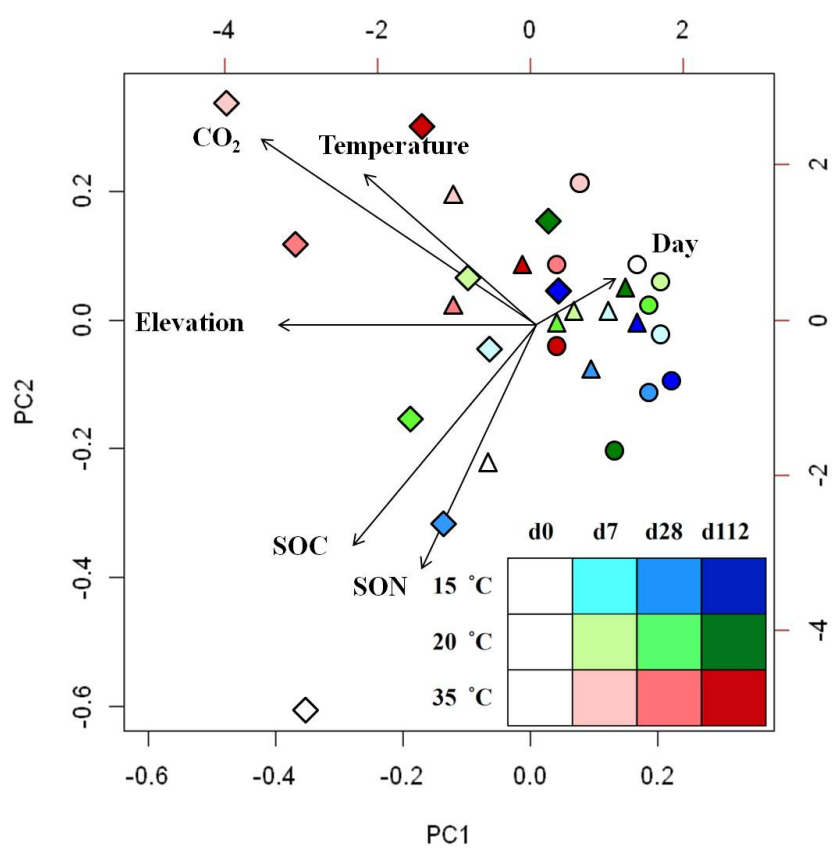

Figure 7. PCA of bamboo soil bacterial communities and environmental properties. Symbols are the same as in Fig. 6.

owing to warming (Allison et al., 2010; Zhou et al., 2011). The present work revealed community structure differences after incubation for only about 4 months, suggesting that the bacterial communities in bamboo soils at elevation are highly sensitive to temperature changes, even though they faced a relatively short-time warming condition.

The responses of phylogenetic abundances to temperature differed. As for Acidobacteria, the abundance generally decreased with increasing temperature. This is in accordance with previous studies showing decreases in the relative abundance of Acidobacteria in warming soils (Xiong et al., 2014; Yergeau et al., 2012). Acidobacteria are known as slow-growing (oligotrophic) bacteria that prefer low nutrient availability (Fierer et al., 2007) and possess high maximum growth efficiency (Roller and Schmidt, 2015). Warming conditions in the soil could increase substrate availability and might favor fast-growing (copiotrophic) microorganisms, which are more sensitive to nutrient availability (Männisto et al., 2016). Thus, the decreases in the abundance of Acidobacteria could reflect their interactions with copiotrophic species. The abundance of Acidobacteria could also be limited by high temperatures (Stark et al., 2015).

Under increased temperature, some phyla in our study responded differently from previous studies. Increasing $\alpha$ Proteobacteria abundance has been observed in short warming conditions (Xiong et al., 2014) and in a range of Antarctic environments (Yergeau et al., 2012). $\alpha$-Proteobacteria are mostly fast-growing (copiotrophic) bacteria and are known to be positively correlated with soil available $\mathrm{C}$ pools $(\mathrm{Ne}-$ mergut et al., 2010). The decreases in the abundance of 
$\alpha$-Proteobacteria in the present study could reflect the decrease in SOC content, which was exhausted by soil respiration $\mathrm{CO}_{2}-\mathrm{C}$ after incubation. Bradyrhizobium of $\alpha$ Proteobacteria at $1800 \mathrm{~m}$ increased at all three incubation temperatures. This genus includes species capable of nitrogen fixation and may significantly contribute to soil function (Yarwood et al., 2009). The increase in their abundance might explain the elevated SON. Moreover, these bacteria are plant-growth-promoting bacteria, stimulating plant growth by fixing $\mathrm{N}_{2}$, increasing the availability of nutrients in the rhizosphere, positively influencing root growth and morphology, and promoting other beneficial plant-microbe symbioses (Vessey, 2003). Their response to incubation temperatures indicates their potential roles in bamboo growth and responses to application of fertilizers under climatic change.

The increase in abundance of $\gamma$-Proteobacteria after incubation in our study differed from that in the soil community sampled at elevated soil temperature. $\gamma$-Proteobacteria showed a lower relative abundance under elevated temperature than in the ambient temperature control (Ren et al., 2015). Within $\beta$-Proteobacteria, the abundant genus Burkholderia is nutritionally versatile and is commonly found in rhizosphere soils. Their functional diversity, including nitrogen fixation and plant growth promotion (Coenye and Vandamme, 2003), could help maintain soil community stability. In addition, Actinobacteria and Bacteroidetes showed variable responses at different temperatures. These phyla also prefer nutrient-rich environments (Nemergut et al., 2010). Differences in vegetation and litter quality among the study sites might explain this variation. Actinobacteria are involved in the organic matter degradation. Under climatic changes, managements of bamboo forests need to consider the responses of Actinobacteria to temperature, especially that in $\mathrm{N}$ fertilizers, since the abundance of this phylum was positively affected by $\mathrm{N}$ fertilization treatments (Zhou et al., 2015). The Mucilaginibacter species of Bacteroidetes are capable of degrading polysaccharides (Pankratov et al., 2007); thus, the increase in their abundance can be explained by the increase in plant residues in the soil. A previous study suggested the relationship of elevation and temperature with the decomposition of recalcitrant $\mathrm{C}$ (Wang et al., 2016a). After decomposition of labile C, the availability of recalcitrant $\mathrm{C}$ can strongly affect the community. Moreover, based on a literature survey by Ho et al. (2017), there is little consistency in oligotrophic and copiotrophic phyla of bacterial communities. The microorganisms can display a variety of metabolic characteristics and adjust between high and low substrate use efficiency to adapt to environmental changes. Therefore, shifts in the relative abundances of bacterial taxa may not necessarily indicate their life strategies as an oligotroph or copiotroph but might just reveal the response of a community to such local factors (Ho et al., 2017). Further study, including more comprehensive temperature gradients and more detailed time-course analysis, will be neces- sary to elucidate the exact influences of temperature on soil communities.

Acidobacteria and $\alpha$-Proteobacteria, which comprised more than $10 \%$ of the communities before incubation, tended to decrease after incubation. Groups with lower abundance before incubation, especially, $\gamma$-Proteobacteria, showed an increasing trend after incubation. These patterns were similar to those shown in communities of a rice paddy and desert soils (Wang et al., 2012; Ren et al., 2015), in which numerically dominant bacterial phyla/classes were reduced, while originally rare groups increased in relative abundance after exposure to environmental changes. These results suggest that shifts in bacterial populations facing environmental changes may follow predictable patterns.

\section{Conclusions}

Our results revealed that an increase in temperature could result in increased soil respiration $\mathrm{CO}_{2}-\mathrm{C}$ and consumption of SOC and SON contents, which directly or indirectly influence the bacterial diversity and structure of bamboo soils at different elevations. In addition, the different responses of bacterial groups to the temperature changes suggest the adaptation of soil communities to global-warmingrelated climatic changes. This study highlights the need for further research on the physiological and ecological roles of soil bacterial members, such as Acidobacteria, $\alpha$ - and $\gamma$-Proteobacteria, in response to climatic change in forest ecosystems.

Data availability. All sequences have been submitted to the Short Read Archives under accession number SRS1923345.

\section{The Supplement related to this article is available online at https://doi.org/10.5194/bg-14-4879-2017-supplement.}

Author contributions. YTL performed statistical analyses; ZJ built statistical models; CYC interpreted ecological rationale; CYC and ZJ formulated the study hypothesis and developed the methodology; and YTL wrote and ZJ and CYC edited the manuscript. All authors read and approved the final manuscript.

Competing interests. The authors declare that they have no competing interests.

Acknowledgements. The authors thank the Ministry of Science and Technology of Taiwan for financially supporting this research under contract number MOST 105-2621-B-001-007. The authors are also grateful to Yu-Shiuan Huang from Biodiversity Research Center, 
Academia Sinica, Taipei, Taiwan, for assisting with molecular analyses. This study is also partly supported by the Strategic Priority Research Program of the Chinese Academy of Sciences (XDB15040000).

Edited by: Denise Akob

Reviewed by: two anonymous referees

\section{References}

Allison, S. D., McGuire, K. L., and Treseder, K. K.: Resistance of microbial and soil properties to warming treatment seven years after boreal fire, Soil Biol. Biochem., 42, 1872-1878, 2010.

Bárcenas-Moreno, G., Gómez-Brandón, M., Rousk, J., and Bååth, E.: Adaptation of soil microbial communities to temperature: comparison of fungi and bacteria in a laboratory experiment, Glob. Change Biol., 15, 2950-2957, 2009.

Castro, H. F., Classen, A. T., Austin, E. E., Norby, R. J., and Schadt, C. W.: Soil microbial community responses to multiple experimental climate change drivers, Appl. Environ. Microb., 76, 999-1007, 2010.

Clarke, K. R. and Gorley, R. N.: Primer v6: user manual/tutorials, Primer-E Ltd, Plymouth, 2006.

Coenye, T. and Vandamme, P.: Diversity and significance of Burkholderia species occupying diverse ecological niches, Environ. Microbiol., 5, 719-729, 2003.

Fierer, N., Bradford, M. A., and Jackson, R. B.: Toward an ecological classification of soil bacteria, Ecology, 88, 1354-1364, 2007.

Hamady, M., Walker, J. J., Harris, J. K., Gold, N. J., and Knight, R.: Error-correcting barcoded primers for pyrosequencing hundreds of samples in multiplex, Nat. Methods, 5, 235-237, 2008.

Ho, A., Lonardo, D. P. D., and Bodelier, P. L. E.: Revisiting life strategy concepts in environmental microbial ecology, FEMS Microbiol. Ecol., 93, fix006, https://doi.org/10.1093/femsec/fix006, 2017.

Huang, C. Y., Jien, S. H., Chen, T. H., Tian, G., and Chiu, C. Y.: Soluble organic $\mathrm{C}$ and $\mathrm{N}$ and their relationships with soil organic $\mathrm{C}$ and $\mathrm{N}$ and microbial characteristics in moso bamboo (Phyllostachys edulis) plantations along an elevation gradient in Central Taiwan, J. Soil Sediment., 14, 1061-1070, 2014.

Keiser, A. D., Strickland, M. S., Fierer, N., and Bradford, M. A.: The effect of resource history on the functioning of soil microbial communities is maintained across time, Biogeosciences, 8 , 1477-1486, https://doi.org/10.5194/bg-8-1477-2011, 2011.

Lane, D. J.: 16S/23S rRNA sequencing, in: Nucleic Acid Techniques in Bacterial Systematics, edited by: Stackbrandt, E., and Goodfellow, M., Wiley, New York, 115-175, 1991.

Lin, G., Rygiewicz, P. T., Ehleringer, J. R., Johnson, M. G., and Tingey, D. T.: Time-dependent responses of soil $\mathrm{CO}_{2}$ efflux components to elevated atmospheric $\left[\mathrm{CO}_{2}\right]$ and temperature in experimental forest mesocosms, Plant Soil, 229, 259-270, 2001.

Lin, Y. T., Tang, S. L., Pai, C. W., Whitman, W. B., Coleman, D. C., and Chiu, C. Y.: Changes in the soil bacterial communities in a cedar plantation invaded by moso bamboo, Microb. Ecol., 67, 421-429, 2014.

Lin, Y. T., Whitman, W. B., Coleman, D. C., Shi, S. Y., Tang, S. L., and Chiu, C. Y.: Changes of soil bacterial communities in bam- boo plantations at different elevations, FEMS Microbiol. Ecol., 91, fiv033, https://doi.org/10.1093/femsec/fiv033, 2015.

Liu, J., Jiang, P., Wang, H., Zhou, G., Wu, J., Yang, F., and Qian, X.: Seasonal soil $\mathrm{CO}_{2}$ efflux dynamics after land use change from a natural forest to moso bamboo plantations in subtropical China, Forest Ecol. Manag., 262, 1131-1137, 2011.

Loreau, M. and de Mazancourt, C.: Biodiversity and ecosystem stability: a synthesis of underlying mechanisms, Ecol. Lett., 16, 106-115, 2013.

Männisto, M., Ganzert, L., Tiirola, M., Häggblom, M. M., and Stark, S.: Do shifts in life strategies explain microbial community responses to increasing nitrogen in tundra soil?, Soil Biol. Biochem., 96, 216-228, 2016.

Nemergut, D. R., Cleveland, C. C., Wieder, W. R., Washenberger, C. L., and Townsend, A. R.: Plot-scale manipulations of organic matter inputs to soils correlate with shifts in microbial community composition in a lowland tropical rain forest, Soil Biol. Biochem., 42, 2153-2160, 2010.

Pankratov, T. A., Tindall, B. J., Liesack, W., and Dedysh, S. N.: Mucilaginibacter paludis gen. nov., sp. nov., and Mucilaginibacter gracilis sp. nov., pectin-, xylan- and laminarin-degrading members of the family Sphingobacteriaceae from acidic Sphagnum peat bog, Int. J. Syst. Evol. Micr., 57, 2349-2354, 2007.

Ren, G., Zhu, C., Alam, M. S., Tokida, T., Sakai, H., Nakamura, H., Usui, Y., Zhu, J., Hasegawa, T., and Jia, Z.: Response of soil, leaf endosphere and phyllosphere bacterial communities to elevated $\mathrm{CO}_{2}$ and soil temperature in a rice paddy, Plant Soil, 392, 27-44, 2015.

Roller, B. R. K. and Schmidt, T. M.: The physiology and ecological implications of efficient growth, ISME J., 9, 1481-1487, 2015.

Rousk, J., Frey, S. D., and Bååth, E.: Temperature adaptation of bacterial communities in experimentally warmed forest soils, Glob. Change Biol., 18, 3252-3258, 2012.

Schloss, P. D., Westcott S. L., Ryabin, T., Hall, J. R., Hartmann, M., Hollister, E. B., Lesniewski, R. A., Oakley, B. B., Parks, D. H., Robinson, C. J., Sahl, J. W., Stres, B., Thallinger, G. G., Van Horn, D. J., and Weber, C. F.: Introducing mothur: open-source, platform-independent, community-supported software for describing and comparing microbial communities, Appl. Environ. Microb., 75, 7537-7541, 2009.

Stark, S., Männistöb, M. K., Ganzert, L., Tiirola, M., and Häggblom, M. M.: Grazing intensity in subarctic tundra affects the temperature adaptation of soil microbial communities, Soil Biol. Biochem., 84, 147-157, 2015.

Vessey, J. K.: Plant growth promoting rhizobacteria as biofertilizers, Plant Soil, 255, 571-586, 2003.

Wang, B. Z., Zhang, C. X., Liu, J. L., Zeng, X. W., Li, F. R., Wu, Y. C., Lin, X. G., Xiong, Z. Q., Xu, J., and Jia, Z. J.: Microbial community changes along a land-use gradient of desert soil origin, Pedosphere, 22, 593-603, 2012.

Wang, H. C., Chou, C. Y., Chiou, C. R., Tian, G., and Chiu, C. Y.: Humic acid composition and characteristics of soil organic matter in relation to the elevation gradient of moso bamboo plantations, Plos One, 11, e0162193, https://doi.org/10.1371/journal.pone.0162193, $2016 \mathrm{a}$.

Wang, H. C., Tian, G., and Chiu, C. Y.: Invasion of moso bamboo into a Japanese cedar plantation affects the chemical composition and humification of soil organic matter, Sci. Rep.-UK, 6, 32211, https://doi.org/10.1038/srep32211, 2016b. 
Wang, Q., Garrity, G. M., Tiedje, J. M., and Cole, J. R.: Naïve Bayesian classifier for rapid assignment of rRNA sequences into the new bacterial taxonomy, Appl. Environ. Microb., 73, 52615267, 2007.

Wu, J. S., Jiang, P. K., Chang, S. X., Xu, Q. F., and Lin, Y.: Dissolved soil organic carbon and nitrogen were affected by conversion of native forests to plantations in subtropical China, Can. J. Soil Sci., 90, 27-36, 2010.

Xiong, J., Sun, H., Peng, F., Zhang, H., Xue, X., Gibbons, S. M., Gilbert, J. A., and Chu, H.: Characterizing changes in soil bacterial community structure in response to short-term warming, FEMS Microbiol. Ecol., 89, 281-292, 2014.

$\mathrm{Xu}, \mathrm{Q}$., Jiang, P., and Xu, Z.: Soil microbial functional diversity under intensively managed bamboo plantations in southern China, J. Soils Sediment, 8, 177-183, 2008.

Yarwood, S. A., Myrold, D. D., and Högberg, M. N.: Termination of belowground $\mathrm{C}$ allocation by trees alters soil fungal and bacterial communities in a boreal forest, FEMS Microbiol. Ecol., 70, 151162, 2009.

Yergeau, E., Bokhorst, S., Kang, S., Zhou, J., Greer, C. W., Aerts, R., and Kowalchuk, G. A.: Shifts in soil microorganisms in response to warming are consistent across a range of Antarctic environments, ISME J., 6, 692-702, 2012.
Zhang, W., Parker, K. M., Luo, Y., Wan, S., Wallace, L. L., and $\mathrm{Hu}, \mathrm{S}$.: Soil microbial responses to experimental warming and clipping in a tallgrass prairie, Glob. Change Biol., 11, 266-277, 2005.

Zhou, G., Zhang, J., Chen, L., Zhang, C., and Yu, Z.: Temperature and straw quality regulate the microbial phospholipid fatty acid composition associated with straw decomposition, Pedosphere, 26, 386-398, 2016.

Zhou, J., Xue, K., Xie, J., Deng, Y., Wu, L., Cheng, X., Fei, S., Deng, S., He, Z., Van Nostrand, J. D., and Luo, Y.: Microbial mediation of carbon-cycle feedbacks to climate warming, Nat. Clim. Change, 2, 106-110, 2011.

Zhou, X., Fornara, D., Wasson, E. A., Wang, D., Ren, G., Christie, P., and Jia, Z.: Effects of 44 years of chronic nitrogen fertilization on the soil nitrifying community of permanent grassland, Soil Biol. Biochem., 91, 76-83, 2015. 